\title{
Research on the Application of Virtual Reality System in Higher Education to Aesthetic Education
}

\author{
Yuan $\mathrm{CHENG}^{1,2, \mathrm{a},{ }^{*} \text { and Chao DU }}{ }^{3, \mathrm{~b}}$ \\ ${ }^{1} \mathrm{Ph}$.D. Candidate at the College of Marxism, Beijing Jiaotong University, Beijing, China \\ ${ }^{2}$ lecturer in Academy Of Fine Art, Qilu Normal University, Ji'nan, China \\ ${ }^{3}$ The Research Center for Literary Theory and Aesthetics \\ Shandong University, Ji'nan, China \\ ajackystudio@163.com, b739236636@qq.com
}

Keywords: Socialist aesthetic education, Virtual reality technology, Cloud computing technology, Virtual reality system of higher education.

\begin{abstract}
With the rapid development of modern media and internet technology, the popularization and application of virtual reality technology and cloud computing technology undoubtedly plays a positive role in promoting the present and future development of human civilization. In recent years, they have expanded their power rapidly, from education to military affairs, from entertainment to medicine, they showed their vitality everywhere. This paper introduces the concept, feature and classification of virtual reality technology and cloud computing technology, proposes the combination of virtual reality technology with cloud computing technology is virtual reality system of higher education, and expand the research of the construction and advantage of aesthetic education.
\end{abstract}

\section{Introduction}

With the rapidly improvement of computer graphics technology, Internet technology and human-computer interaction simulation technology, the traditional computer-centric information processing and transmission environment was unable to meet the needs of the user's experience. Virtual reality technology and cloud computing technology were developing as an important way to improve the efficiency of daily work and strengthen the various applications of true feelings. They provide advanced simulation ideas for the research and decision-making of all kinds of traditional and modern science, its simulation and cloud functions greatly save manpower, material resources and improve work efficiency, while it directly avoid the irreversible loss caused by authenticity development. At present, due to the restrictions of resources, such as space, time and practical conditions, aesthetic education has met some problems during the development. The introduction of digital virtual reality technology and cloud computing technology, will provides a good idea and platform for the construction of aesthetic education. 


\section{Brief Introduction of Virtual Reality Technology and Cloud Computing Technology}

\section{The Concept, Development, Characteristics and Classification of Virtual Reality Technology}

Concept. Virtual reality (VR) is a kind of immersive interactive environment based on computable information, Specifically, it is a virtual environment that uses computer technology to generate realistic visual, auditory, taste and tactile integration, users can interact with the objects in virtual environment in the usual way by means of necessary equipment, so that users can have the feelings and experiences of immersed in the real environment. Therefore, we call it "illusion technology". The change of science and technology promotes this technology's integration with new concept, new content, new way and new method, making the content of human-computer interaction richer and vividly, and make the way of human-computer interaction more natural and harmonious.

Characteristics. In 1993, Burdea G published "Virtual Reality System and Application" in the Electro93 International Conference, proposed the three characteristics of virtual reality technology, namely: immersion, interaction, imagination. Immersion refers to the ability a user puts into the virtual scene generated by computer, and the user may has the feeling of being immersed in the virtual scene. What it sees, hears, smells, touches, and feels exactly the same as in the real world. It is the core of the virtual reality system. Interactivity refers to the ability a user uses to interact with various objects in virtual scene. It is the key factor of man-machine harmony. When the user enters the virtual environment, he can interact with the multi-dimensional information environment through various sensors, the manipulated object in virtual environment can respond to user's operation, which is similar to real scene. Interactivity includes the operability of the object, the natural degree of feedback the user gets from the environment, the degree of motion the object moves according to the laws of physics in virtual environment and so on. Imagination refers to that, through the user's immersion in the "real" virtual environment and interact with it, he can get perceptual and rational knowledge from the qualitative and quantitative comprehensive integrated environment, so he can deepen the concept, sprouting new ideas and resulting in a leap in understanding. Therefore, the virtual reality is not only a interface combined a user with the terminal, but also allows users to immerse themselves in this environment to acquire new knowledge, improve the perceptual and rational understanding, resulting in new ideas. After inputting this idea into the system, the system will display the processed status in real time or feedback to the user by sensor device. So repeatedly, this is a learning - creation - re-learning - re-creation process. We can say that virtual reality is an activity that inspires people's creative thinking.

\section{The Concept of Cloud Computing Technology}

Why there is a "cloud" in "cloud computing", it is from an allusion. Early in the development of the Internet, network engineers often drawing some sketches in the case description, in these sketches, the pictures of the clouds are often used to represent the interconnection network. So the Internet will have this interesting name called "cloud", and a new generation of computing rely on the Internet inherit the name, which is known as "cloud computing".

As a new technology in the past two years, cloud computing has no unified concept, here we refer to Wikipedia for the definition of "cloud computing": Cloud computing is 
a kind of computing model, it can provide dynamically scaled virtual resource to users through Internet as the way of service. While users don't need to know how to manage infrastructure that supports cloud computing.

For such a concept, it may be too obscure to understand, with the most popular words to express, its meaning is: on a personal computer, there is no need to install any software, all of the procedures and software are installed in every servers of the network service provider, when the user needs to use a certain software, he only need to send a request to the server through a computer, the corresponding server will receive the request, after a series of procedures, the results will send back to the user's computer.

\section{Brief Introduction of Aesthetic Education}

Aesthetic education, namely, develop the ability of beauty through training people to know the beauty, experience the beauty, feel the beauty, appreciate beauty and create the beauty, so that we can have the ideal of beauty, the sentiment of beauty and the quality of beauty. It has been a long time since aesthetic education was appeared, which can dating back to Schiller, whose On the Aesthetic Education of Man can be viewed as the first book of aesthetic education, it is the first time to put forward a systematic and comprehensive theory of aesthetic education, and expound the necessity of aesthetic education and the significance of aesthetic education profoundly. Schiller tried to cultivate the ideal person, perfect person and harmonious development by means of aesthetic education, which had a great influence on the theory of aesthetic education in the world.

In China, the beginning of aesthetic education can dating back to Cai Yuan pei, he has put forward the famous "five education simultaneously" educational policy, namely, army national education, utilitarian education, moral education, worldview education and aesthetic education, among which aesthetic education is very unique. He has put forward replace religion with aesthetic education, and stressed that aesthetic education is a kind of important world outlook education, he thought that aesthetic education is free, popular and progressive, which inspired many scholars at that time.

Nowadays, aesthetic education in school is very universal, more and more people have recognized the necessity of it. The main task of aesthetic education in schools includes: cultivate and improve the students' ability to feel the beauty; cultivate and improve the students' ability to appreciate beauty; cultivate and improve the students' ability to express and create beauty; cultivate and improve the students' ability to pursue the interests of life and ideal state. The key of aesthetic education is socialist aesthetic education .Socialist aesthetic education serves to construct socialist spiritual civilization and cultivate students' spiritual beauty. It uses the good things in real life and the thoughts or activities of the advanced people reflected in artistic image to infect the educated. It affects students' emotions, imagination, thoughts, will and personality extensively and deeply. It can enrich the cultural and spiritual life of the school, arouse students' emotional experience, help them to cultivate lofty sentiments and improve the socialist consciousness. Aesthetic education can not only help students to understand the reality, but also can develop their ability of observation, imagination, image thinking and creativity. The main principles of socialist aesthetic education are as follows: firstly, the combination of ideological nature and artistry. Secondly, the combination of aesthetic education content and real life. Thirdly, the combination of 
emotional experience and logical thinking. Finally, The unity of art content and expression method.

\section{The Advantages of Virtual Reality Technology and Cloud Computing Technology}

The advantage of virtual reality technology is that it is a comprehensive technology, including computer graphics, multimedia, artificial intelligence, sensor technology and parallel processing technology, it can be applied in various fields with high efficiency, and make subversive changes in stereotypes people have on the computer, that is boring, stiff and passive. This subversive change is its advantage:

1. Relying on the highly integrated disciplines;

2. Human presence;

3. Large-scale integration of systems or environments;

4. Diversity and standardization of data representation, large capacity of data storage, high speed data transmission, distributed and parallel data processing

As the Internet application mode proposed in recent years in Internet domain, cloud computing reflects the most advanced technology. In this industry, which is changing and developing rapidly, the change brought by the advantages of cloud computing makes the industry full of fresh blood. From the perspective of optimizing the industrial layout and promoting the professional division of labor, and then to the operation and maintenance level of cloud computing, from the upgrading of resource efficiency, and then to the angel of reducing the operation of investment, reducing the cost of management, cloud computing has its unique advantages.

\section{Research on the Construction and Advantages of the Application of Virtual Reality System in Higher Education to Aesthetic Education}

In the field of aesthetic education, the traditional mode of teaching still occupies the leading position. And the application of virtual reality technology, can allow students to learn in personal experience, this is more direct and more convincing than abstract preaching. This kind of affinity interaction has a qualitative difference with passive viewing. As some scholars have said: this new technology will bring us a new educational thinking, solve the problems that can't be solved in the past, and bring a series of major changes in education.

\section{The Construction of Virtual Reality System in Higher Education}

The virtual reality system of higher education is based on the combination of virtual reality technology with cloud computing technology, the essence of it is the construction of virtual environment, which should be supported by the following conditions: it must have interaction with the user, real-time feedback to the user information and the user should has the autonomy of operation. As another important component of the system, cloud computing technology's accession will optimize the allocation of aesthetic education resources, improve the utilization of resources, reduce the cost of management and promote the cooperation of colleges and universities. The construction of the virtual reality system of higher education is shown in figure 1: 


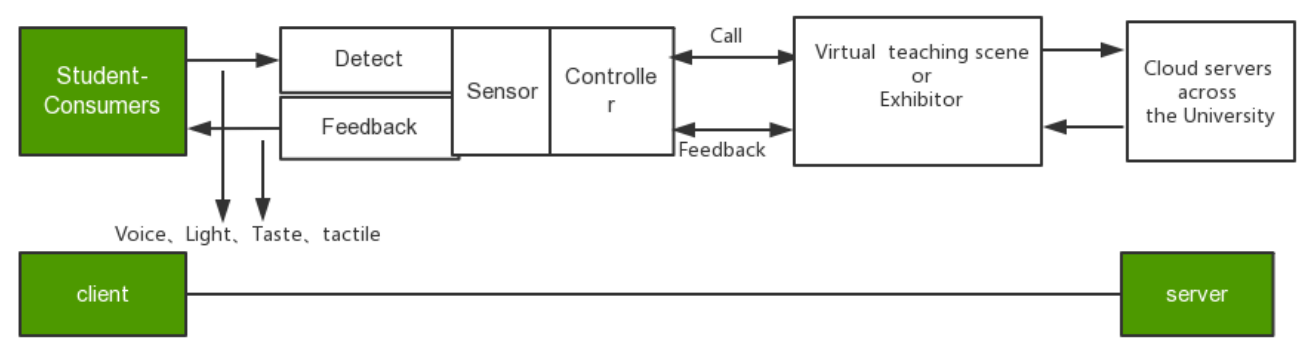

Figure 1. The construction of the virtual reality system of higher education

\section{Research on the Advantages of the Application of the Virtual Reality System in Higher Education to the Teaching of Aesthetic Education}

The application of the virtual reality system in higher education to aesthetic education is consistent with aesthetic education. The purpose of aesthetic education is to cultivate students' aesthetic consciousness, in order to improve the students' aesthetic level and to stimulate students' ability to create beauty. As aesthetic is abstract and subjective, and most of the cultivation of aesthetic consciousness can't separate from the visual, hearing and other basic perception. Therefore, the practice of art is one of the ways to realize aesthetic education. Although the virtual reality does not have the specific physical meaning of the shape and structure, but its construction is based on the reality of the prototype, it will present a real feeling in the human brain, the practical application is in the form of "visible and intangible" in the user's brain. In the process of aesthetic education, through this way, students' cognitive activities are the same as in real life; this is a practical activity with a real sense of perception. Students in the virtual world can not only participate in the activities of aesthetic objects, but also feel the change of aesthetic objects through virtual perception; this kind of professional perception and practice is consistent with the purpose of aesthetic education at present.

The application of virtual reality system in higher education to aesthetic education teaching is consistent with the high efficiency and low cost advocated by the aesthetic education. For schools, huge manpower and material resources will make the school in debt and difficult to survive, in this case, reduce the various costs will undoubtedly become an important issue for the survival and development of universities. The application of virtual reality system in higher education is of high efficiency and low cost, which has become an important way to solve the problem. A one-time investment in hardware, sustainable development of software, makes it has the low-cost in the construction that the physical construction cannot match.

The application of virtual reality system in higher education to aesthetic education teaching is consistent with the desire to integrate all kinds of resources in aesthetic education. The current art education materials was not only confined to the university and not limited to book knowledge, a lot of resources among universities and university abroad (such as painting exhibition, photography exhibition etc.) can meet the aesthetic needs of students to a large extent. As a carrier of the technology which is negotiable and communicable, virtual reality technology carry the crystallization of all kinds' resources. When students learn and practice with this technology, they can not only break the boundaries of knowledge, but also cultivate the aesthetic appreciation from the macro point of view. In addition, because the virtual reality technology has the characteristics of remote display, the teachers of universities can support the virtual 
reality technology through the network, which can realize the synchronous teaching in universities and good interaction with students, this advantage can integrate resources to a large extent.

The application of virtual reality system in higher education to aesthetic education teaching is consistent with breaking the limits of space and time advocated by aesthetic education. The lack of space, the difficulty to coordinate time, has always been a practical problem in the teaching of aesthetic education. The traditional curriculum study can't meet the growing demand of aesthetic education, break through the limitation of time and space, participate in the art practice in all directions can deepen the aesthetic. Although, in recent years, colleges has held a large number of artistic activities, but it is still difficult to meet the full range of aesthetic needs. This makes some new teaching models can be used, such as collaborative work teaching and situational teaching. These methods are some attempts that the application of virtual reality system in higher education to aesthetic education, so that teaching is no longer subject to location, distance and time constraints, this can make inter-university and international inter-school cooperation more fluid, make sure the sharing of resources, allowing students to participate in specific situations, so as to cultivate aesthetic.

\section{Summary}

Many of the characteristics of virtual reality technology and cloud computing technology, is the advantage of its application to aesthetic education. The introduction of virtual reality system in higher education solves the contradiction in current aesthetic education, such as focus on theory and ignored in practice, lacking of resources etc, it greatly meet the popularity and development of aesthetic education, and combine all kinds of aesthetic resources together perfectly. The development of aesthetic education is a long-term systematic project, and the introduction of the virtual reality system in higher education will undoubtedly inject new vitality to the development of aesthetic education.

\section{References}

[1] Byrne, Niall, "Cloud Computing," Accountancy Ireland, 42rd ed, vol.3.2010, pp.48-51.

[2] Charles De Garmo,"Aesthetic Education," Journal of Educational Psychology, 10rd ed, vol.4.1913, p611.

[3] David "The Future of Aesthetic Education," Journal of Aesthetic Education, 17rd ed, vol.1.p15.

[4] Harry S, "The Preparation of Teachers for Aesthetic Education," Art Education Reston, 20rd ed, vol.3.1967, p29.

[5] Larry F. Hodges; Barbara O. Rothbaum, "Virtually Bette? Virtual Reality System" Cyber Psychology \& Behavior, 4rd ed, vol.1.1998, p.405.

[6] LeBlanc, Leonard, "Virtual reality system developed for projects,"Offshore, 57rd ed, vol.6.1997, p30.

[7] Stanley S," Aesthetic Education: An Area of Study, "Art Education - Reston, 24rd ed, vol.8.1971, p16. 